\title{
From Ship to Sheep: An Ethnographic Analysis of Guam's Colloquial Chamorro English
}

\author{
Clarisa Garcia Quan, Ph.D. \\ University of Guam
}

\begin{abstract}
Guam Colloquial Chamorro English (GCCE) and Guam Standard English (GSE) are two dominant varieties of English heard spoken on the Micronesian island of Guam. Many speakers, especially the older generation fluent in the island's indigenous language Chamorro, are either GCCE dominant or style shift between GCCE and GSE. This study describes some phonological, lexical, and semantic differences between GCCE and GSE, then explains some general contexts of their use using Dell Hymes' Ethnography of SPEAKING model. This paper is a partial response to the need for cultural descriptions and analyses of English language use in Micronesia, and an attempt to account for English language use data using the Ethnographic model, as suggested by Dr. Y.Kachru in a read speech at the 2006 IAWE Conference in Tokyo.
\end{abstract}

Keywords: World Englishes, linguistics, sociolinguistics, linguistic anthropology

\section{Introduction}

In this study, Dell Hymes' mnemonic SPEAKING model will be used to analyze Guam Colloquial Chamorro English (GCCE) and its more standard variant, that I choose the call Guam Standard English (GSE) to test goodness of fit: how well the model explains and differentiates both GCCE and GSE's various contexts of use. References are taken from personal observations, a popular radio show called Malafunkshun that features skits in both GCCE and GSE, and a very popular comic book English the Chamorro Way, published and reprinted at least thrice in the 1980s and 1990s by Dave Santos, Martin Leon Guerrero, Vince Leon Guerrero, (Ex-Senator) Ben Pangilinan, Michele Santos, ThereseMatanane, and Dan Tydingco, all of whom are Chamorro and non- linguistics trained.

\section{Background}

As stated in a previous study (Quan 2011), I chose to label the variety of English spoken on Guam as Colloquial Chamorro English rather than Chamorro Dialect of English because of the social, historical, and governmental problems of differentiating between "dialect" and "language," (Hudson, 1996, q.v.), and because of the lack of status and full status connected to both terms, respectively. Furthermore, I chose the label Guam Standard English rather than American Standard English to avoid the imposition of the "ideal" acrolect that is American Standard English (ASE) and to show that GSE is linguistically distinct from other varieties of American English, at least in intonation and lexicon, but not necessarily in morphology nor syntax.

\subsection{B. Kachru's World Englishes Model}

As stated in a previous study, (Quan 2011), English language use on Guam does not easily fit in BrajKachru's three concentric circles model.His model does notaccount for code switching nor style shifting that balanced multilinguals and multistylistic-able speakers engage in freely. However,Kachru's model can be modified to fit Guam's speech situation. The boundaries separating the inner and outer circles must be changed to broken lines to allow for the style shifting of speakers, who can move in and out of the first two circles, or between GSE and GCCE, depending on context. The first illustrates Kachru's original model. The second is the suggested modification of it (2011). 


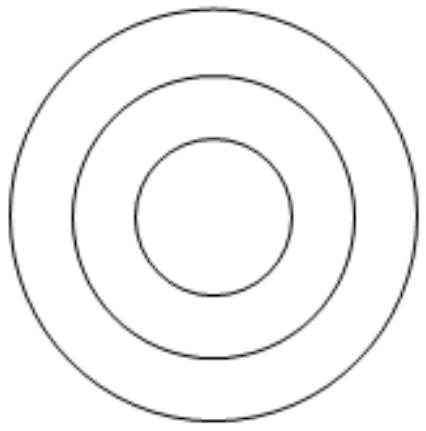

Fig.1: Kachru’s Original Model

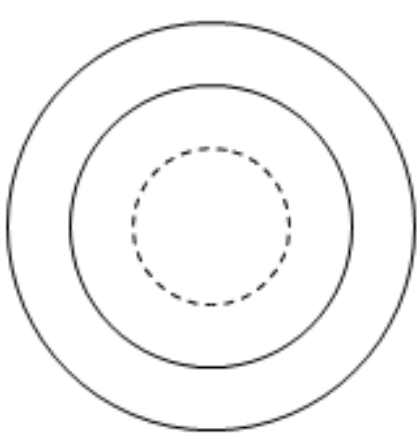

Fig.2: Modified Model for Guam

Hymes SPEAKING model, may therefore better account for GCCE/GSE contexts of use, as well as otherEnglishes' contexts of use in other complex multigenerational, multilingual, multiracial, multiethnic speech communities.

\section{Dell Hymes' SPEAKING mnemonics model applied to GCCE and GSE}

\section{- Setting \& Scene}

Macro: Guam, an island in the Mariana Islands, in Micronesia

Micro: GCCE: homes, restaurants, bars, parishioners in churches:

Also in informal, familiar, familial settings where there are

conversations among family and friends from the same or similar ethnic backgrounds.

GSE Guam Standard English: used in more formal settings:

Classrooms, the media, sermons in churches, hearings in court, newspapers

Although many varieties of English can be heard on Guam because of it racial and linguistic diversity, Guam Colloquial Chamorro English (GCCE) and Guam Standard English (GSE) stand out. Both are spoken by the island's biggest and most influential group, the indigenous Chamorros, and other locals and long term residents. The distinct sounds of English thatChamorros and other locals speak on Guam are partially influenced by Chamorro, the indigenous Austronesian language of Guam, Rota, Tinian, and Saipan in the Marianas Archipelago of Micronesia. Guam's Colloquial Chamorro English is a largely non-stigmatized variety of English with borrowed lexicon not only from Chamorro and Spanish but also from other languages of immigrants and residents from the Philippines, Japan, Korea and other Asian countries. Colonized by Spain for over 300 years, then taken over by the United States from 1898 after the Spanish American War, Guam remains an organized unincorporated territory of the United States with an estimated population of around 160,000 as of 2010 .

\section{- Participants}

GCCE and GSE speakers, hearers: Chamorros and some Guamanians;

Also children ofother ethnicitieswho grew up on island, with local peers speaking English

Generational/age-grading: Older Chamorros use GCCE more than younger ones, who prefer the GSE variant regardless of setting.

Observers/hearers: other ethnicities on island, especially first-generationimmigrants

The presence of so many ethnicities and languages on Guam has resulted not only in many Englishes, but also a nativized form of English - GCCE- spoken by and associated with the biggest ethnic group, the indigenous Chamorros. The many variants of English on Guam have also resulted in a linguistic or accent meta consciousness sometimes expressed in accent mimicry of different Englishes spoken by Chamorros as well as first generation Filipinos, Koreans, Chinese, Japanese, Chuukese, and mainland Americans. The resulting humor can diffuse the tension that sometimes results from the presence of many people from different backgrounds. Of course, some of those mimicked can and do sometimes, feel offended. 
Local and long-term residents can identify speakers' accents based on their Englishes as long as they are exposed long enough and surrounded by enough people who speak different variants of English. Every time I ask my students if they can identify the ethnicities or native languages of speakers based on the way they speak English, the majority of them say yes. The rich mix of Chamorros, Filipinos, mainlanders, Japanese, Korean, Chinese, Micronesians, Thais, Vietnamese, and Indians living on a small island has resulted in a populace very much aware of speakers' ethnicities based on their English accents. For Guam residents, different Englishes in general and Colloquial Chamorro English in particular, are rich resources not only for language use but also for jokes, teasing, and humor - language play. A very popular radio show on the island in the early 2000 s owes much of its popularity to the Chamorro anchors' ability to do just that. The show's hosts led by Chris "malafunkshun" Barnett style shift freely between GSE and GCCE, and mimic the accents of the different ethnic groups using skits, and songs to discuss sometimes sensitive social issues and raise awareness of social, familial, political, and cultural issues. Themales hosts' use of different "voices" and speaking styles, from falsetto to deep authoritarian, results in humorously cushioning and masking what could otherwise be painful, sensitive, or even offensive, topics.

Guam has always had immigrant settlers. But second-generation Guam resident immigrants no longer sound like their first generation Asian or Micronesian immigrant parents. Rather, they grow up acquiring the English of their local peers - Guam Standard English (GSE) with several features of Guam's Colloquial Chamorro English (GCCE). This makes it difficult, if not impossible, to identify the specific ethnicities of immigrants' children based on their English alone, especially by the second generation, after they have grown up on the island and gone to school with local peers. So the adage of peers first, teachers next, and parents last as models for English language style acquisition does seem to apply to Guam local speakers as well.

Many older bilingual Chamorros code switch between Chamorro and GCCE, with GCCE as their only English-speaking style. Many of the middle-aged generation, regardless of their Chamorro proficiency, style shift between GCCE and GSE in informal and formal contexts, respectively. Informal contexts would include fiestas, family gatherings, family conversations, gossip, and other casual meetings and get-togethers.

Participants using GSE include native-born and Guam-raised residents of Guam, regardless of ethnicity. It is not uncommon for a second-generation Korean eighth grader at a local school to use GSE with some GCCE lexicon and intonational patterns though the parents are nearly monolingual Korean speakers.

\section{- Ends}

GCCE: Communication, rapport/solidarity and "we" inclusive or one-ness among speakers\& hearers.

GSE: establishes the seriousness and formality of a situation

Middle-aged speakers who are GSE dominant switch to GCCE to evoke Chamorro-ness and or for special effect. The younger generation, many of whom are GSE dominant also can, when they wish to, style-shift between GSE and GCCE for the same reasons. Younger speakers may be heard more frequently using the standard, rather than the colloquial, form. Many young speakers increasingly regard GSE and by extension, Standard American English (SAE), as ideal. One could classify GCCE as a symbol of Brown and Gilman's (1960) concept of "solidarity," of closeness and we-ness among Chamorros and locals, whereas GSE is the preferred variant of "power," of the media and government.

Sometimes, speakers use GCCE for humor and play even though they do not normally have the accent. Some second or third generation children of immigrants can style shift between GSE and GCCE to emphasize solidarity, especially those among Chamorro peers and friends. A speaker changing from one variant to another can mean one of several things: the speaker wants to let the other know they are of the same ethnicity; he may want to establish closeness; perhaps he may be seeking a favor and he believes that using GCCE may increase his chances of getting it; or he may do it for teasing, humor, or fun.

\section{- Acts Or Act Sequences}

Style shifting between GCCE in more informal personal settings like the

Home and in informal gatherings, and GSE in more formal ones, e.g.,

School and the media.Code switching between Chamorro and GCCE/GSE. 
Act sequences of GSE and GCCE are not generalizable because they are largely determined by the context: setting, participants, and topics. So a conversation may be comprised of code switching between Chamorro and GSE and GCCE, or style shifting between GSE and GCCE, or be purely GSE in formal and GCCE in informal settings. Act Sequences may not be applicable to a general description of GSE and GCCE, and may only apply to specific analyses of specific speech acts or events, for example, a political speech with Question-and-Answer at the end. This can also include interactions between parents who speak in Chamorro, GCCE, or the other native languages, and children who respond only in GCCE or GSE.

\section{- Key}

"Key", composed of triggers that lead to conversational shifts between GCCE and GSE and vice versa,can include the following:

1.Chamorro expressions in English can trigger the change from GSE to GCCE. Examples are nai, lai, fan, that are commonly heard in GCCE. This can be as simple as one of the interlocutors suddenly and contextually uttering "Yes fan", "No lai," "Come on fanlai""Please fan" or "Susmariajose" in the midst of GSE conversation that can then lead to a switchto GCCE.

2. Chamorro perjoratives in conversation: "Eeylaña, Eeylokwe, Sana talipas, Diaplo (devil)(intestines), Chada" among others,can trigger the shift to GCCE. Lana's meaning and impact can range from the traditionally offensive to one that is only slightly so, depending on context. Chadaimplies rotten eggs and perhaps by extension, infertility.

2. Switching topics from informal familial topics or gossip to formal topics like serious legal issues for example can trigger the change from GCCE to GSE.

3. Direct quotes from the law or mediaentails the use of GSE. Radio and TV hosts use GSE.

4. Asides, personal comments and emotional reactions can trigger GCCE.

5. Terms of address that establish closeness: "Hey (Hafa) Chelu" (sibling), "Hey Pari" or "Hey par" (from Spanish compadre), "Hey bro" (brother), "Hey Gatchong"[friend], "Hey prim" (primo-fr. Spanish for male cousin), " can lead to GCCE use. "Pari/Par" is tied to the Chamorro cultural compadre godparent/parent's close relationship.

6. Greetings that start with "EeiHafa" together with a nod of the head or handshake set the tone for possible GCCE use.

\section{- Instrumentalities}

General linguistic features of GCCE include phonological, and lexical characteristics that are distinct from GSE. Guam Colloquial Chamorro English - GCCE - is largely not stigmatized most probably because it is the variant of English used by and associated with Chamorro speakers, who have historically held political and economic power on the island. Since the transition from U.S. military rule to civilian government in mid- $20^{\text {th }}$ century Guam, civilian governors, most senators, and most local judges have been Chamorros. All but one of the presidents of the island's university except one, have been Chamorros. A number of big businesses on Guam are Chamorro-owned. Therefore, the island's indigenous Chamorro language, as well as the English variants associated with those who hold political and economic power on the island, i.e., Chamorros and mainland Americans, reflect the status of their speakers.

As previously mentioned, the many variants of English on Guam have also resulted in a linguistic or accent meta consciousness sometimes expressed in accent mimicry of different Englishes spoken by first generation Filipinos, Koreans, Chinese, Japanese, Chuukese, and mainland Americans. The resulting humor can diffuse the tension that sometimes results from the presence of many ethnicities on a small island. Of course, some of those mimicked can, and sometimes do, feel offended. Chris Malafunkshun Barnett, in his radio show, includes humorous skits of conversations between the different groups. Listeners' reaction is almost always, laughter "ha haha" (soundcloud.com).

The most noticeable features of GCCE are: its sounds first, some of its non-English lexicon second, then finally, SAE words that have acquired new GCCE meanings and changed to different parts of speech. These are enumerated and described below.

Labov's (1972) variable rules format is used to describe the striking and oftentimes mimicked sound features of GCCE because in essence, Labov'sclaim about variable rules capture many of the characteristics of GCCE. For the most part, no Chamorro speaker uses all of the GCCE variables all of the time because they either code 
switch or style shift between languages or between GSE and GCCE; and, for the most part, no Chamorro or even a second generation non Chamorro Guam resident, is unable to use some of the variables, or never uses a few of them, at least some of the time. Finally, GCCE speakers need not use all the linguistic features listed below. But they do use at least some of them some of the time. Several cartoon examples below illustrate the variable use of language in GCCE.

Below are some of the most common phonological features of GCCE that make its speakers readily identifiable as local. Local residents who have lived on the island long enough are able to identify and label the speakers as Chamorro or local. This linguistic metaconsciousness is reflected in several editions of English the Chamorro Way, published and reprinted at least thrice in the 1980s and 1990s by non-linguistics trained Chamorros. The largely humorous cartoons and captions in this comic book highlight the sound features, lexicon, and semantics of GCCE and other Englishes. The cartoons used in this paper are from the comic books.

Below are ten of the most evident phonological rules of GCCE are summarized below (q.v. Quan 2011):

1. Rising terminals in all sentences, even declaratives

2. Final obstruent devoicing, where sounds like [bdgv] change to [ptkf] word finally. Examples are [bap, gat, bik, beIf, ] for "Bob, God, big, bathe".

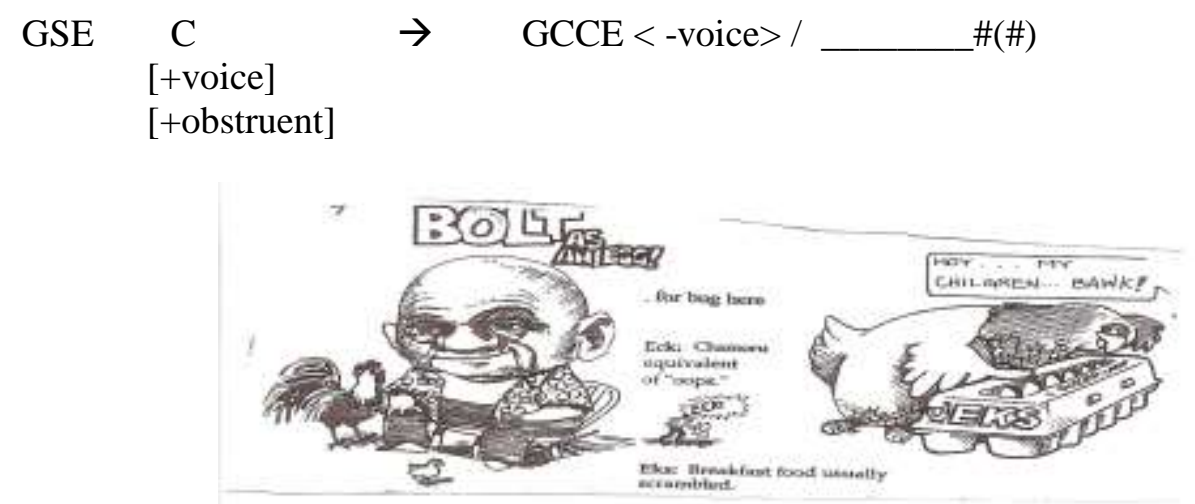

Fig. 3: Final obstruent devoicing From English the Chamorro Way (reprinted with permission)

3. $/ \Theta / \partial / \rightarrow</ \mathrm{t} / \mathrm{d}>/ \# \#$

$\langle\mathrm{f} / \mathrm{v}>\mathrm{l}$ but (\#\#) (word medially and finally).

Examples are [tink, den, mæf, beIf, bæfrum] for "think, then, math, bathe, bathroom"

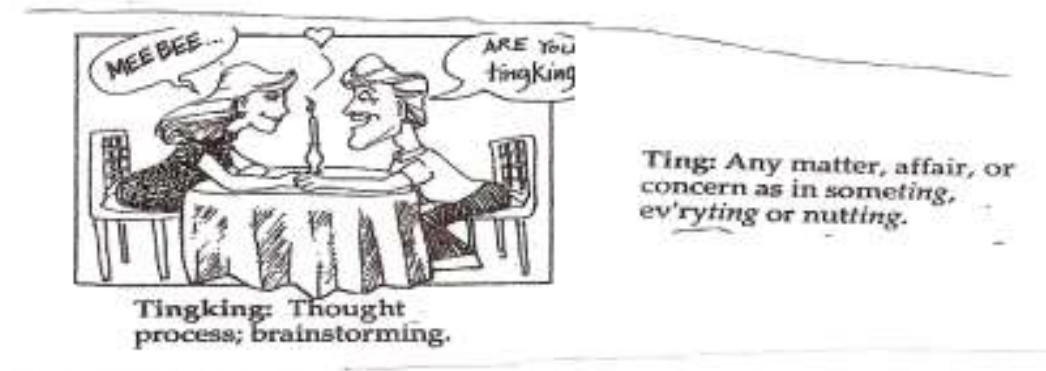

Fig. 4: $[\Theta / \partial]$ pronounced $<\mathrm{t}, \mathrm{f}, \mathrm{d}, \mathrm{v}>$

From English the Chamorro Way (reprinted with permission)

4. $\quad \mathrm{v} \rightarrow<\mathrm{b}>/$ \#\#_ (word initially), but

$\rightarrow<$-voice $>/ \ldots$

Examples are [bæt, beIf, beIfin] for "vat, bathe, bathing"

5. $\mathrm{z} \rightarrow\langle d \mathrm{~d}\rangle \mid$ \#\#___ (word initially)

$\rightarrow\langle\mathrm{s}\rangle$ (everywhere else).

Examples are [dzori?,dzip, dzibra, bus, busin] for "zori, zip, zebra, buzz, buzzing” 


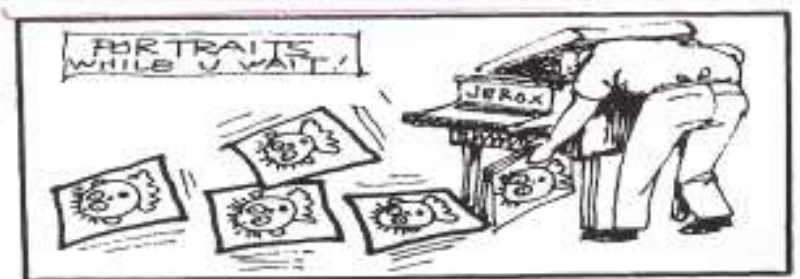

\section{Jerox: The process of Photocopying.}

Fig. 5: $[\mathrm{z}] \rightarrow\langle\mathrm{dz}\rangle$ or $\langle\mathrm{s}\rangle$

6. $\int \rightarrow\langle\mathrm{s}\rangle$

From English the Chamorro Way (reprinted with permission)

Examples are [sæm, mæsin, mes] for "sham, mashing, mesh"

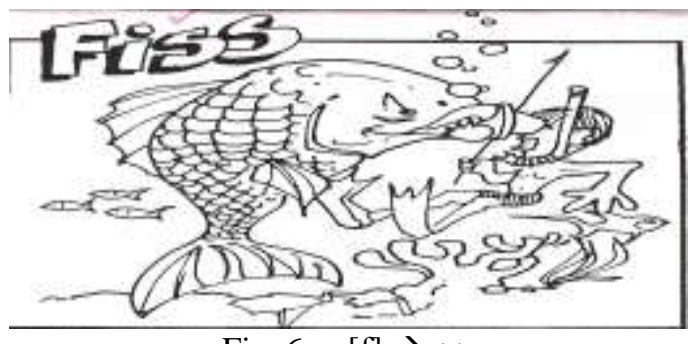

Fig. 6: $\left[\int\right] \rightarrow\langle s>$

7. $3 \rightarrow<d y>$ or $<\mathrm{dz}>$ but

From English the Chamorro Way (reprinted with permission)

$\rightarrow<\mathrm{ts}>$ I____ \#\# (word finally).

Examples are [dzadza, garats] for "ZsaZsa, garage"

8. $1 \rightarrow\langle\mathrm{t}\rangle /$ (for Spanish words in Chamorro), or

$\rightarrow<w ?>$ I__ \#\# (word finally)

or simply deleted

Examples are [butdosa, piw?] for "bulldozer, pill"; and [lugat] for Spanish "lugar"/place

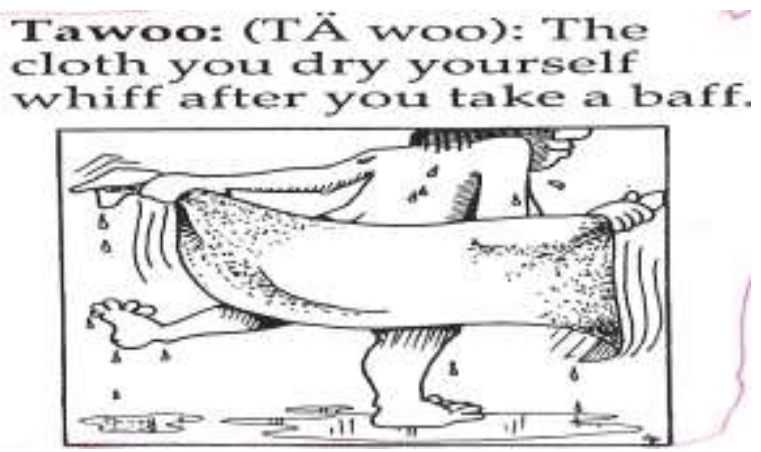

Fig. 7: [1] $\rightarrow\langle t>$ or $\langle w$ ? $>$ or deleted

From English the Chamorro Way (reprinted with permission)

9. Consonant cluster simplification or $\mathrm{CC}(\mathrm{C})(\mathrm{C}) \rightarrow \mathrm{C}$

So "asked" can be pronounced [æs]

10. No [i/I] contrast, where "pill" and "peel" can be pronounced the same way [piw?]

(see "fiss" [fis] supra).

Chamorro words and expressions in GCCE abound. Among them arelainai fan - three words that Chamorro/English dictionaries claim to have no meaning but actually have pragmatic meaning and impact (q.v., Quan 2016, in progress).

The morphology of GCCE remains close to GSE/SAE. The same is true of its syntax. 


\section{-Norms Of Interaction}

Whether using GCCE or GSE, the same traditional cultural and speaking norms apply. Older speakers speak with authority; younger ones speak with respect and deference when addressing older speakers. Younger ones must use titles of respect when addressing older speakers.

Titles of respect include the following:

"Auntie+name", "Uncle+name" e.g., Auntie Joanne; Uncle Paul;

"Tan+female proper name" - e.g., Tan Rosa; "Tun+male name" - e.g., Tun Juan;

Nina or Nino for godmother or godfather, and,

Nana or Tata for grandmother or grandfather.

Greeting grandparents and much older family members or family friendsalways come with kissing the hand while saying "Nyora" for female and "Nyot" for male addressees. These are an integral part of the rules and norms of talk for both GSE and GCCE.

\section{-Genre}

I have coined the terms Guam Standard English (GSE) as distinct from Standard American English (SAE), and Guam Colloquial Chamorro English (GCCE). The latter is the primary focus of this study.

\section{Conclusion}

This study is an attempt to see the closeness of fit between Hymes' SPEAKING MODEL and a general description of Guam's (G)SE and (G)CCE 's contexts of use. Is Hymes' model applicable to the analysis of the speech situation on Guam? Evidently, but it would also be germane to use SPEAKING to analyze actual discourse, or real-speech events where interactants actually use one or the other variant, style shift between the two variants, code switch between languages and even other variants of Englishes spoken on Guam. The model can indeed explain the reasons behind the shiftswithbreadth and depth. SPEAKING promises to be a useful model, tool, and guide in the analysis of thevarieties of language and the cultural contexts of their use.

\section{References}

[1] Barnet, Chris. (2005). "Malafunkshun". CD. Guam.

[2] Barnet, Chris. (March 2016). Malafunkshun :Taya License. UTube. Available: Soundcloud.com.

[3] Bolton, Kingsley. Fourth diasporta: world Englishes today. In Handbook of World Englishes, pp.240-270.

[4] Bolton, Kingsley. Varieties in world Englishes. In Handbook of World Englishes, pp. 289-312. http://dx.doi.org/10.1002/9780470757598.ch17

[5] Cunningham, Denis, Ingram, D.E. and Sumbuk, Kenneth., eds. Language Diversity in the Pacific. UK: Multilingual Matters, 1996.

[6] Crystal, David. English as a Global Language.GB: Cambridge University Press, 2004.

[7] Images. English the Chamoru Way. Guam: Images Publishing, 1992.

[8] Hudson, R A. Sociolinguistics. GB: Cambridge University Press, 1985, 2005.

[9] Hymes, Dell. Foundations of Sociolinguistics. PN:University of PennsylvaniaPress, 1974, 1985.

[10] Hymes, Dell. Ways of Speaking. In Explorations in the Ethnography of Speaking.Eds. Richard Bauman and Joel Sherzer, NY: Cambridge University Press, 1993, pp. 433-452.

[11] Kachru, Braj, Y.Kachru\& C. Nelson, eds.The Handbook of World Englishes. MA: Blackwell, 2006.

[12] Kachru, Braj. World Englishes and culture wars. In Handbook of World Englishes, pp. 446-472. http://dx.doi.org/10.1002/9780470757598.ch25

[13] Kachru, Yamuna. Plenary Speech read at the IAWE Conference, Nagoya, Japan, 2006.

[14] Quan, C. "From Esteemed Colleagues" to "Steamed Collix": Language use and awareness in Guam's Colloquial Chamorro English. Micronesian Educator, vol.14, 2011.

[15] Santos, D., M. Santos, J. Tydingco, J. Pangilinan. English the Chamorro Way. Guam: Images Publishing, 1990. 